Article

\title{
Study of Multiple Land Use Planning Based on the Coordinated Development of Wetland Farmland: A Case Study of Fuyuan City, China
}

\author{
Bingmiao Zhu, Xun Zhu *, Ran Zhang and Xiaolong Zhao \\ School of Architecture, Harbin Institute of Technology, Harbin 150001, Heilongjiang, China; \\ Zhubingmiao_LA@163.com (B.Z.); fjylzr@163.com (R.Z.); zhaoxiaolong@hit.edu.cn (X.Z.) \\ * Correspondence: zhuxun@hit.edu.cn
}

Received: 8 November 2018; Accepted: 3 January 2019; Published: 8 January 2019

check for updates

\begin{abstract}
Fuyuan City is located in the black soil region of northeast China. Its fertile soil and flat terrain provide a reliable guarantee for the scale, intensification, and standardization of farmland. A large amount of land resources that can be used for the national food base has been developed, and the contradiction between the need for wetland protection and arable land development has become increasingly prominent. Based on the remote sensing data of 2000, 2005, and 2010, this paper simulates the future land use/land cover changes structure in Fuyuan City based on the Markov Chain model. According to the characteristics of Fuyuan City's structure, economy, society, and natural environment, within the overall planning of the city, we explore three scenarios: business-as-usual scenarios, farmland conservation scenarios, and wetland conservation scenarios. The results revealed the following: (1) Under the business-as-usual scenario, the rapid development of Fuyuan City showed the characteristics of the continued expansion of urban area and the reduction of farmland and wetland area in 2020 compared with 2010. (2) Under farmland conservation scenarios, farmland was well protected and stable, while construction land expansion was restricted. (3) Under wetland conservation scenarios, wetland increased dramatically, which mainly derived from farmland, grassland, and unused land. According to the result, optimized countermeasures are proposed to balance the coordinated development of farmland and wetlands, to deepen the multiperiod planning of land use in Fuyuan City and to provide data support and a basis for decision-making.
\end{abstract}

Keywords: land use; farmland; wetland; scenario planning; Markov Chain model

\section{Introduction}

Land use/land cover changes are the result of the interaction between humanity and nature, and they involve complex mechanisms and processes. Recommendations have been offered to reorient land use planning practices to maximize ecosystem services delivery [1]. Wetlands are one of the most important ecological environments on the Earth. As a transitional region between terrestrial ecosystems and aquatic ecosystems, wetlands have unique hydrological characteristics and play a vital ecological role [2,3]. Since the 1980s, nature reserves with wetland ecosystems as the main object of protection have been established one after another [4]. Countries around the world are paying increasing attention to the problem of ecological function degradation caused by the conversion of wetlands to farmland and construction land or the reduction of wetland areas caused by natural factors, such as habitat degradation [5], biodiversity loss [6], water quantity and quality declines [7,8], and reduced carbon sequestration [9]. To respond to these emerging environmental problems, the first necessary step is to quantify the spatiotemporal patterns of agricultural encroachment into natural areas.

Since limited land resources are used for both grain production and ecological protection, in the past five years, scholars have carried out multiscenario simulation predictions for land use to balance 
the competing relationships between different types of land use. Stewart and Cao et al. used genetic algorithms to spatially optimize the allocation of land resources and used the ideal point method to solve multiobjective decision problems $[10,11]$. Land use simulation prediction models mainly include quantitative structural simulations, such as Markov Chain models, multivariate statistical models, system dynamic models, and spatial structure simulations such as the Conversion of Land Use and its Effects (CLUE) model and CA model [12-14]. In the analysis of land use oriented by farming civilization, three land use spatial layout scenarios were simulated for farmland protection, construction and development, and ecological protection (Chao Yueqing, 2013) [15,16]. Alternatively, it is divided into three scenarios: business-as-usual trends, ecological and environmental protection management, and urban planning and regional development (Xu Xiaojuan, 2017) [17,18]. These studies demonstrate that the Markov Chain model is the most accurate method for quantitative research.

During the past 50 years, natural wetland farmland has been an important factor in the loss and degradation of wetland in Fuyuan City; after nearly 50 years of large-scale agricultural development, the natural wetland area has been lost, and a series of regional ecological environment problems have arisen [19]. Therefore, effective analysis and simulation of land use change is crucial for correcting ecological environment management and ensuring the safety of agricultural food production. Domestic and foreign scholars have carried out a lot of research work on the landscape change of the marsh wetland in Sanjiang Plain, the environmental effects of land cover change, and the impact of land use change on ecosystem service functions [20-24]. However, research has not been able to reveal in depth the laws of farmland in the region. There are still gaps for different scenarios of land use planning and wetland environmental protection under different planning conditions in contractive urban and rural areas. At the macro level, the land policy of China's land administration departments is mainly reflected in quantity control rather than specific spatial planning. The purpose of this paper is to combine the Markov model with multicriteria evaluation, to predict and simulate land use patterns in different scenarios, and to quantify the mechanism in the land type transfer process to verify whether the relevant departments' macrolevel land use policies are reasonable.

\section{Research Area and Work Flow}

\subsection{Study Area}

Located in the easternmost part of China, Fuyuan City is in the triangular area where the Heilongiiang River and the Wusuli River meet (Figure 1). The total area is $6262.48 \mathrm{~km}^{2}$ (Figure 2). It is a national-level ecological demonstration area, and the ecological resources are well preserved. As the hometown of Chinese salmon, it is said to have more than $70 \%$ green coverage. It plays a decisive role in ensuring national food and regional ecological security. There is approximately $68 \%$ of cultivated land and $16 \%$ of wetlands. The economic output of Fuyuan City is dominated by an agricultural economy. Agriculture is dominated by plantations and animal husbandry, followed by forestry and fisheries. In the past 20 years, agricultural land in Fuyuan City has experienced unprecedented expansion. It is expected that this trend will continue. The area of agricultural land increased from 249,000 hectares in 2005 , which accounted for $41.2 \%$ of the county's total land area, to 506,000 hectares in 2009 , which accounted for $83.7 \%$. This kind of sharp change in agricultural land growth has negative impacts on land cover such as the decline in land use and biodiversity and water resource pollution. 


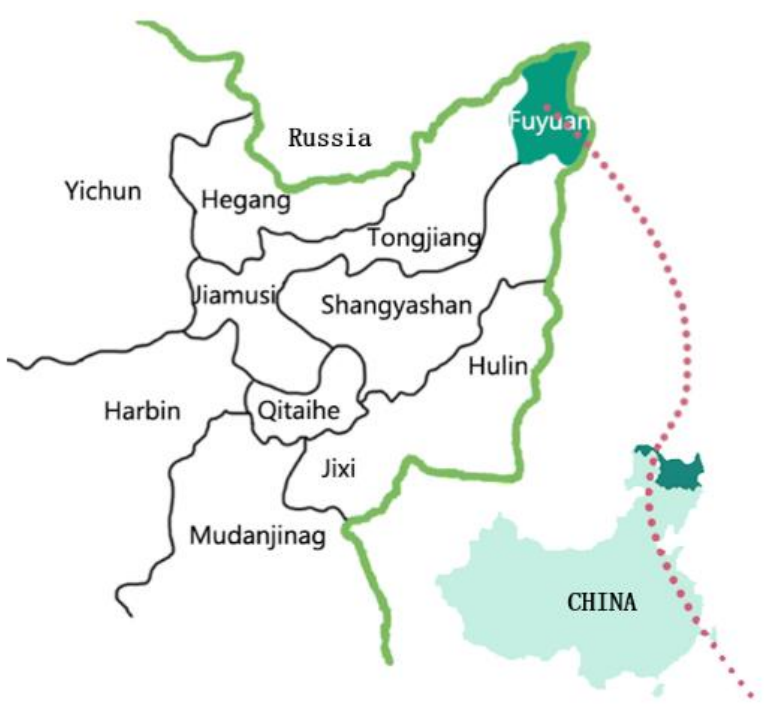

Figure 1. Location of study area: Fuyuan City, Heilongjiang Province, China. Source: According to Fuyuan administrative location self-painting.

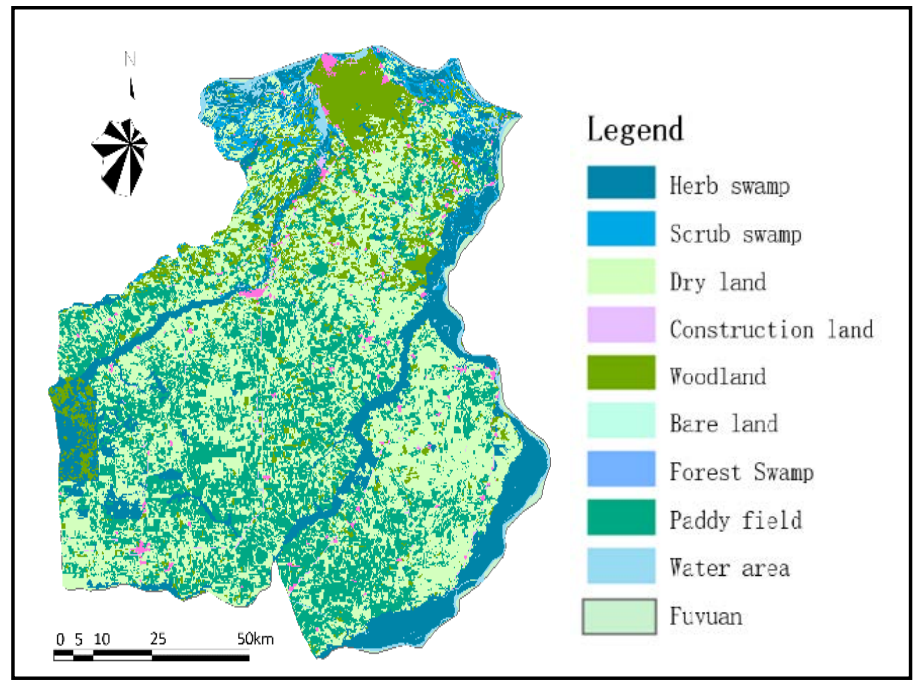

Figure 2. Land Use in 2010 in Fuyuan City. Source: Land use status map of Fuyuan County, Heilongiiang Province and Landsat5TM image data of Fuyuan County.

\subsection{Sources of Data}

The basic data include the land use vector data provided by the Center for Resources and Environmental Data of the Chinese Academy of Sciences in 2000, 2005, and 2010. According to the characteristics of land use in Fuyuan City, with reference to the latest land use classification and coding table (GB T 21010-2017), the types of land use were divided into nine categories: forest land, paddy field, dry land, bare land, water area, construction land, forest swamp, shrub swamp, and herbaceous swamp (Figure 3). In this paper, the Shuttle Radar Topography Mission (SRTM) data were used to obtain 2010 Digital Elevation Model (DEM) data from geospatial data clouds for generating the gradient information. From the acquired land use data of the study area, the area of various land types was used as a benchmark area by the software, and the optimal analysis grid scale was obtained based on the comparison and determination of $100 \mathrm{~m}$. 


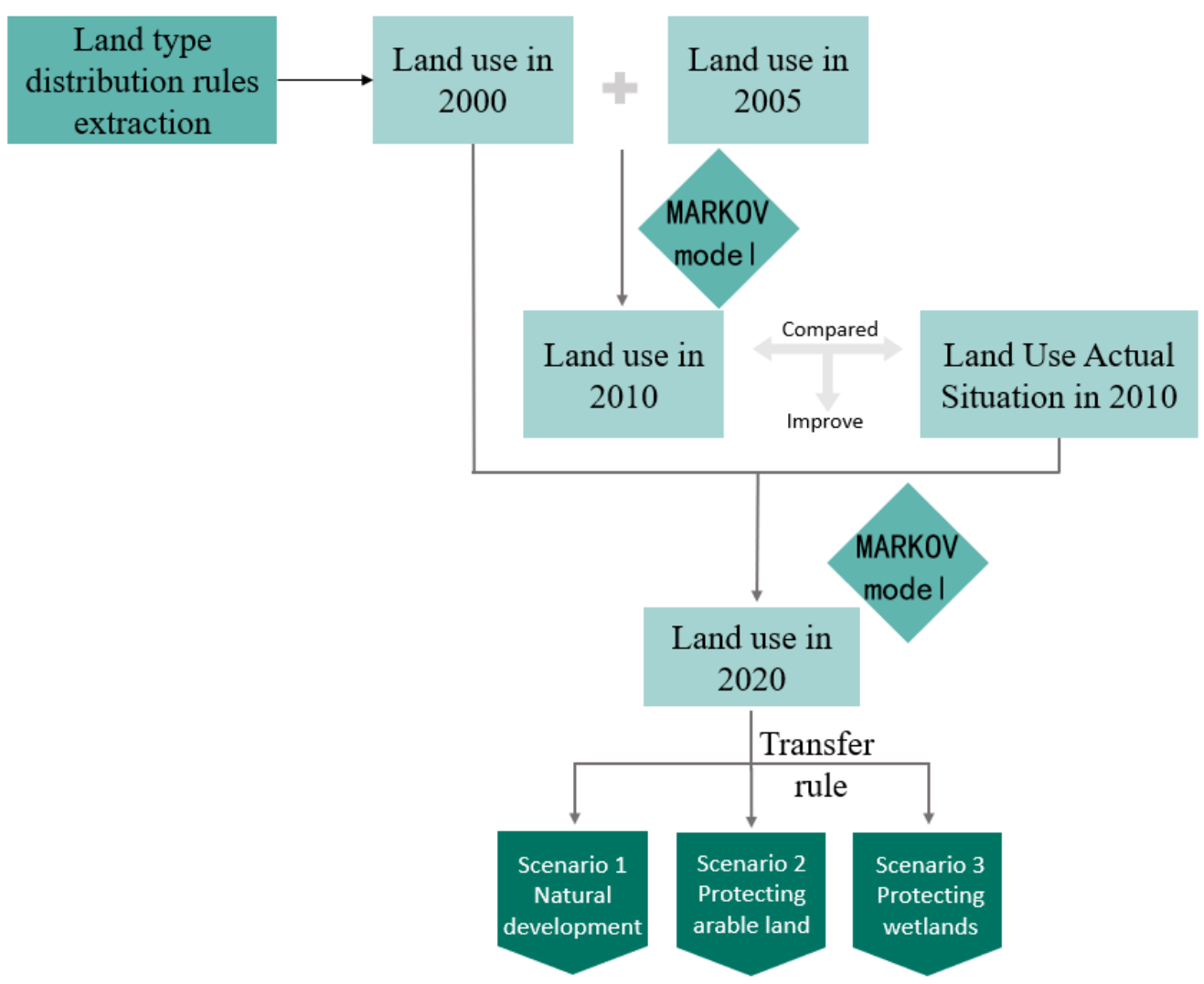

Figure 3. Work flow.

\subsection{Work Flow}

This paper takes Fuyuan City as an example. We adopted ArcGIS 10 technology to superpose the analysis of land use maps in 2000 and 2005 to obtain a land use transfer matrix, and we used the Markov Chain model to predict the land use in 2010. We next compared the results with the actual land use in 2010 and corrected it to predict the land use in 2020. Then, using the shift matrix to analyze land use/land cover changes in Fuyuan City from 2000 to 2010, combined with the Markov Chain model and multicriteria evaluation (MCE) method, the transfer rules were divided into three scenarios: business-as-usual scenarios, protected arable land scenarios, and protected wetland scenarios. The prediction of land use/land cover changes under the three scenarios in Fuyuan City in 2020 was forecasted, and a comparative analysis was conducted to provide corresponding conclusions (Figure 3).

\section{Research Methods}

\subsection{Markov Chain Model}

The Markov Chain model is used to predict the conversion of land use in a certain area. There are two main components: the transfer matrix and the transition probability matrix, which represent the period and number of land transfers from one land use type to other types [25]. The Markov chain is widely used in land use type transition probabilities. According to the stochastic process, the moment of $T+1$ is only related to the state of $T$, and the nature of unrelated to the state of other moments determines the moments. The trend of the system changes. Its expression is as follows:

$$
S_{t+1}=S_{t} \times P_{i j}
$$


where $S_{t+1}$ and $S_{t}$ are land use states at time points $t+1$ and $t$, respectively, and $P_{i j}$ is a transition probability matrix that satisfies the following conditions:

$$
\begin{gathered}
0 \leq P_{i j} \leq 1 \\
\sum_{j=1}^{n} P_{i j}
\end{gathered}
$$

\subsection{Calculating the Transition Probability Matrix Using Markov Chains}

In the Markov module in the IDRISI software, the land use maps for 2000, 2005, and 2010 were input. The time interval was 5 years. Through cross-tabulation analysis, the land use type transition probability matrix was obtained from 2000 to 2010 (Table 1).

Table 1. The Transition Probability Matrix of Fuyuan City 2000-2010.

\begin{tabular}{cccccccccc}
\hline $\mathbf{2 0 0 0}$ & Woodland & $\begin{array}{c}\text { Paddy } \\
\text { Field }\end{array}$ & $\begin{array}{c}\text { Dry } \\
\text { Land }\end{array}$ & Bare Land & $\begin{array}{c}\text { Water } \\
\text { Area }\end{array}$ & $\begin{array}{c}\text { Construction } \\
\text { Land }\end{array}$ & $\begin{array}{c}\text { Forest } \\
\text { Swamp }\end{array}$ & $\begin{array}{c}\text { Scrub } \\
\text { Swamp }\end{array}$ & $\begin{array}{c}\text { Herb } \\
\text { Swamp }\end{array}$ \\
\hline Woodland & 0.6807 & 0.1143 & 0.1767 & $1.49 \times 10^{-6}$ & 0.0008 & 0.0085 & $9.49 \times 10^{-7}$ & 0.0078 & 0.0111 \\
Paddy field & 0.0356 & 0.5279 & 0.4015 & $4.17 \times 10^{-6}$ & 0.0018 & 0.0097 & $2.31 \times 10^{-7}$ & 0.0058 & 0.0177 \\
Dry land & 0.0542 & 0.3448 & 0.5210 & $9.92 \times 10^{-6}$ & 0.0077 & 0.0133 & $3.62 \times 10^{-7}$ & 0.0213 & 0.0376 \\
Bare land & 0.0020 & 0.0891 & 0.0448 & 0.0025 & 0.7029 & 0.0014 & 0 & 0.0215 & 0.1358 \\
Water area & 0.0016 & 0.0176 & 0.0333 & $1.66 \times 10^{-6}$ & 0.6323 & 0.0152 & $6.88 \times 10^{-7}$ & 0.0398 & 0.2603 \\
Construction land & 0 & 0 & 0 & 0 & 0 & 1 & 0 & 0 & 0 \\
Forest swamp & 0.3474 & 0.0538 & 0.1061 & 0.0025 & 0.0079 & 0.0336 & 0.0025 & 0.0957 & 0.3530 \\
Scrub swamp & 0.0513 & 0.0354 & 0.0882 & 0.0002 & 0.0128 & 0.0233 & 0.0002 & 0.4718 & 0.3170 \\
Herb swamp & 0.0054 & 0.0675 & 0.1251 & $7.73 \times 10^{-6}$ & 0.0287 & 0.1431 & $7.73 \times 10^{-7}$ & 0.0166 & 0.6136 \\
\hline
\end{tabular}

\subsection{Multiple Context Conversion Rule Settings}

This paper compares the driving forces of land use/cover change in Sanjiang Plain with domestic experts and finds that human factors play an increasingly important role in the change of land pattern in Fuyuan City. In terms of the protection and development of cultivated land, the Heilongjiang Provincial Land Use Master Plan (2006-2020) clearly stated that it is necessary to do a good job in field support and increase the area of paddy fields. In terms of ecological protection factors, the "Decision of the State Council on Implementing the Scientific Outlook on Development and Strengthening Environmental Protection" issued in December 2005, for the first time, proposed "environmental priority" in the State Council's documents, reflecting the historicity of China's environmental policy. The transformation, therefore, under the mandatory control of national policies, was that the loss of forest land and wetland area slowed down.

The setting of scenarios is closely related to the major issues about which policymakers in the region are currently concerned. Our calculation of MCE depends on physical, socioeconomic, and regional characteristics, including constraints and factor conditions [18]. The former condition is to constrain the analysis to a specific area. In this study, the Boolean criterion is used for constraint processing. The value of the region that does not consider the conversion is 0 , and the value of the region that considers the conversion is 1.

In view of the future demand for land in Fuyuan City and to comprehensively consider the current situation of land use in Fuyuan City and future economic and social development strategies, we set up three scenarios-business as usual (I), arable land protection (II), and ecological protection (III) - and carried out a land use simulation under these different scenarios.

(1) Scenario I-business as usual. It is based on its own developmental process. The quantitative demand for land use is mainly based on the transition matrix from 2000 to 2010, and the Markov model is used to predict the land use change in 2020. In this way, we formulated the transfer rule matrix under this scenario (Figure 4).

(2) Scenario II-farmland conservation. Guided by policies, according to the regulations for the strict protection of arable land in the "Fushun City Land Use Master Plan" and the "Songjiang 
Plain Sanjiang Plain Agricultural Comprehensive Development Experimental Zone Construction Plan," the quantitative requirements for land use are mainly to ensure food security and control. The number of transfers out of paddy fields and drylands will give priority to the protection of high-quality contiguous arable land to reduce the occupation of cultivated land by other land types, to reduce the possibility of the conversion of cultivated land to other land, and to protect agricultural land on the basis of the transfer matrix.

(3) Scenario III-wetland protection. Based on the ecological protection red line, the quantitative requirements for land use should be taken into account to improve the regional ecological environment. Water areas, forest lands, and wetlands (herb swamps, shrub swamps, and forest swamps) should be designated nonconvertible areas and other reasonable layouts to ensure ecological control and the protection of ecologically sensitive areas.

Figure 4 summarizes the methodology of the multiscenario Goal/Markov conversion process. By designing land use development propensity models, it can be used to represent land use quantitative dynamics. As shown in Figure 5, the land use types for each scenario can be represented by different circles, where the color of each circle (cultivated land, wetland, water, forest land, construction land) represents the transfer rule for each scenario. Ultimately, the outcome of this matrix can identify the Markov transition rules for land use change.

Woodland Paddy field Dry land Bare land Water area Construction land Forest Swamp Scrub swamp Herb swamp

\begin{tabular}{|c|c|c|c|c|c|c|c|c|c|}
\hline Woodland & 1 & 1 & 1 & 0 & 0 & 0 & 1 & 1 & 1 \\
\hline Paddy field & 1 & 1 & 1 & 1 & 1 & 0 & 1 & 1 & 1 \\
\hline Dry land & 1 & 1 & 1 & 0 & 1 & 0 & 1 & 1 & 1 \\
\hline Bare land & 0 & 0 & 0 & 1 & 0 & 0 & 0 & 0 & 0 \\
\hline Water area & 1 & 0 & 1 & 1 & 1 & 0 & 0 & 1 & 1 \\
\hline Construction land & 1 & 1 & 1 & 0 & 0 & 1 & 0 & 1 & 1 \\
\hline Forest Swamp & 1 & 1 & 1 & 1 & 1 & 1 & 0 & 1 & 1 \\
\hline Scrub swamp & 1 & 1 & 1 & 0 & 1 & 0 & 1 & 1 & 1 \\
\hline Herb swamp & 1 & 1 & 1 & 0 & 1 & 0 & 1 & 1 & 1 \\
\hline
\end{tabular}

Figure 4. The transfer rule matrix under business-as-usual scenarios. Note: 0 Infeasible, 1 Feasible. Intramatrix representation into list transformation.

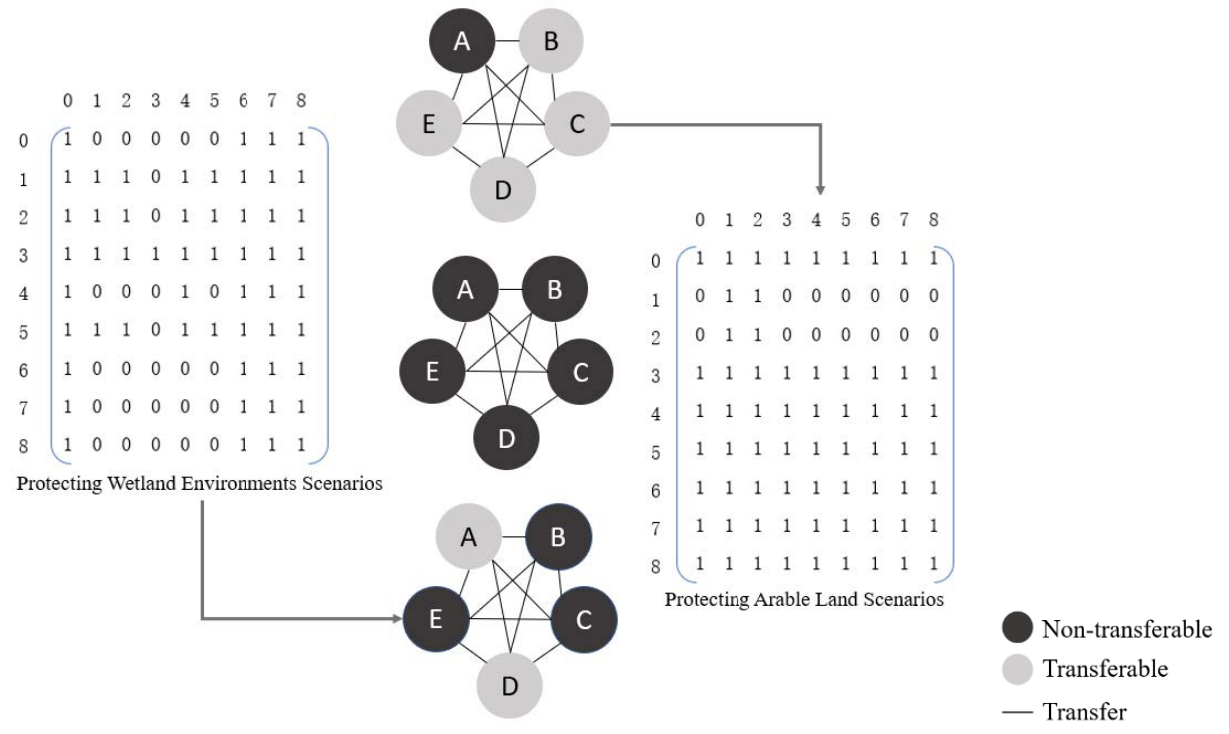

Figure 5. Multiobjective transition rule matrix. (Note: 0 woodland, 1 paddy field, 2 dry land, 3 bare land, 4 water area, 5 construction land, 6 forest swamp, 7 shrub marsh, 8 herb swamp. An Arable land, B Wetlands, C Woodland, D Construction land, E Water area). 


\section{Results and Analysis}

According to the results of the transformation matrix, the Markov model was used to simulate the distribution of land use patterns in 2010. Based on a Kappa analysis of the Markov model's time prediction accuracy, the Kappa statistic on the 10-year time scale from 2000 to 2010 is 0.802 , which shows that the consistency between the simulated map and the actual land use map is good. In addition, this indicates that the model is reliable for Fuyuan and can be used to predict future land use patterns under different scenarios. The land use situation under three scenarios in Fuyuan City in 2020 is shown in Table 2.

Table 2. Land use structure under different scenarios $/ \mathrm{hm}^{2}$.

\begin{tabular}{cccccc}
\hline Land Type & $\mathbf{2 0 0 0}$ & $\mathbf{2 0 1 0}$ & 2020 Scenario 1 & 2020 Scenario 2 & 2020 Scenario 1 \\
\hline Woodland & $54,490.19$ & $56,590.41$ & $37,111.86$ & $37,094.06$ & $52,993.62$ \\
Paddy field & $139,362.6$ & $168,175.1$ & $183,061.3$ & 187,936 & $170,194.4$ \\
Dry land & $265,806.9$ & $231,887.4$ & $231,029.8$ & 252,291 & $208,841.1$ \\
Bare land & 14.69 & 4.44 & 3.45 & 0.23 & 3.45 \\
Water area & 6889.95 & 9538.26 & $12,272.49$ & $20,629.08$ & $25,506.61$ \\
Construction land & $11,395.62$ & $12,198.32$ & $25,509.37$ & 9986.86 & $10,117.73$ \\
Forest swamp & 303.65 & 18.05 & 109.803 & 108.81 & 158.22 \\
Scrub swamp & $10,341.69$ & $12,807.02$ & $14,291.25$ & 7807.42 & $15,706.2$ \\
Herb swamp & $89,777.17$ & $87,163.33$ & $74,993.14$ & $62,528.95$ & $94,861.12$ \\
\hline
\end{tabular}

\subsection{Analysis of the Quantitative Structure of Land Use in Three Scenarios}

\subsubsection{Business-as-Usual Scenario}

The simulation results under the business-as-usual scenario are basically in line with the 2020 plan for land use in Fuyuan City. Compared with the land use in 2010, the area of paddy fields will be significantly expanded by 2020 , with an increase of $13,583.38 \mathrm{hm}^{2}$, with a relatively concentrated distribution; construction land will increase by $18,151.6 \mathrm{hm}^{2}$ and there will be a certain increase in the number of forest lands. The drylands and herbaceous marshes will be degraded to a certain extent and will be $21,105.06 \mathrm{hm}^{2}$ and $14,117.64 \mathrm{hm}^{2}$ less than in 2010, respectively.

\subsubsection{Farmland Conservation Scenario}

Under the arable land protection scenario, the arable land has a high stability and the distribution is concentrated and contiguous (Figure 6). From the results, we can see that by 2020, the wetlands, forest lands, and water areas will have shrunk significantly compared to 2010, while the dry land, paddy fields, and construction land will have increased significantly. From 2000 to 2020, the area of paddy fields will increase by $48,573.44 \mathrm{hm}^{2}$. The area of dry land will increase by $20,403.58 \mathrm{hm}^{2}$ compared to 2010, which is an increase of $41,580 \mathrm{hm}^{2}$ compared to the dryland of the business-as-usual scenario, accounting for $7.19 \%$ of the total area, an increase of nearly $200 \%$. Forest swamps also have a significant increase over natural growth scenarios. At the same time, the increase in arable land mainly comes from land use types, such as wetlands and forest lands, while construction land growth will be stable. This shows that in the context of cultivated land protection, urban development will not stop. 


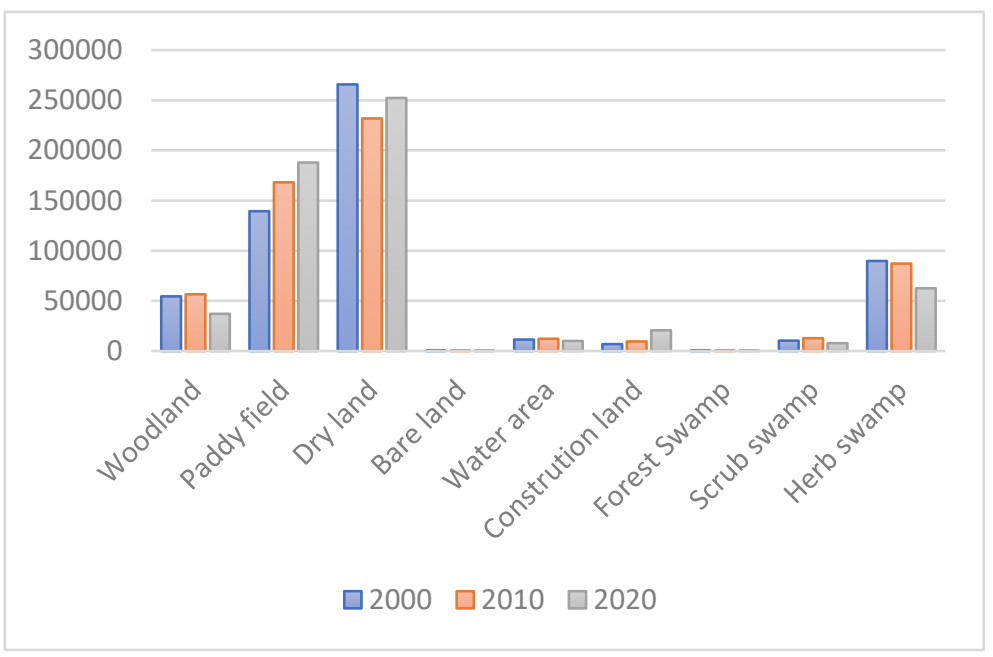

Figure 6. Protection of cultivated land scenarios land use.

\subsubsection{Wetland Environments Protection Scenario}

Under this scenario, forest land and wetlands are well protected (Figure 7). Wetlands are the main land types in Fuyuan City, and there are fewer occurrences. Herbal swamps and shrubs and swamps show a clear upward trend, and the forecast is higher than that of 2010 , with $7697.78 \mathrm{hm}^{2}$ and $2899.17 \mathrm{hm}^{2}$, respectively; forest swamps, shrub swamps, and herbaceous swamps increase by $48.41 \mathrm{hm}^{2}, 1414.95 \mathrm{hm}^{2}$, and $1987.97 \mathrm{hm}^{2}$, respectively, more than business-as-usual scenarios, which is a relatively slow growth rate of $21.3 \%$. Paddy fields and construction land remain stable in the region, while the dry land is reclaimed from the farmland and is reduced to $23,046.32 \mathrm{hm}^{2}$ by 2020 . This shows that wetland protection is a relatively long-term process.

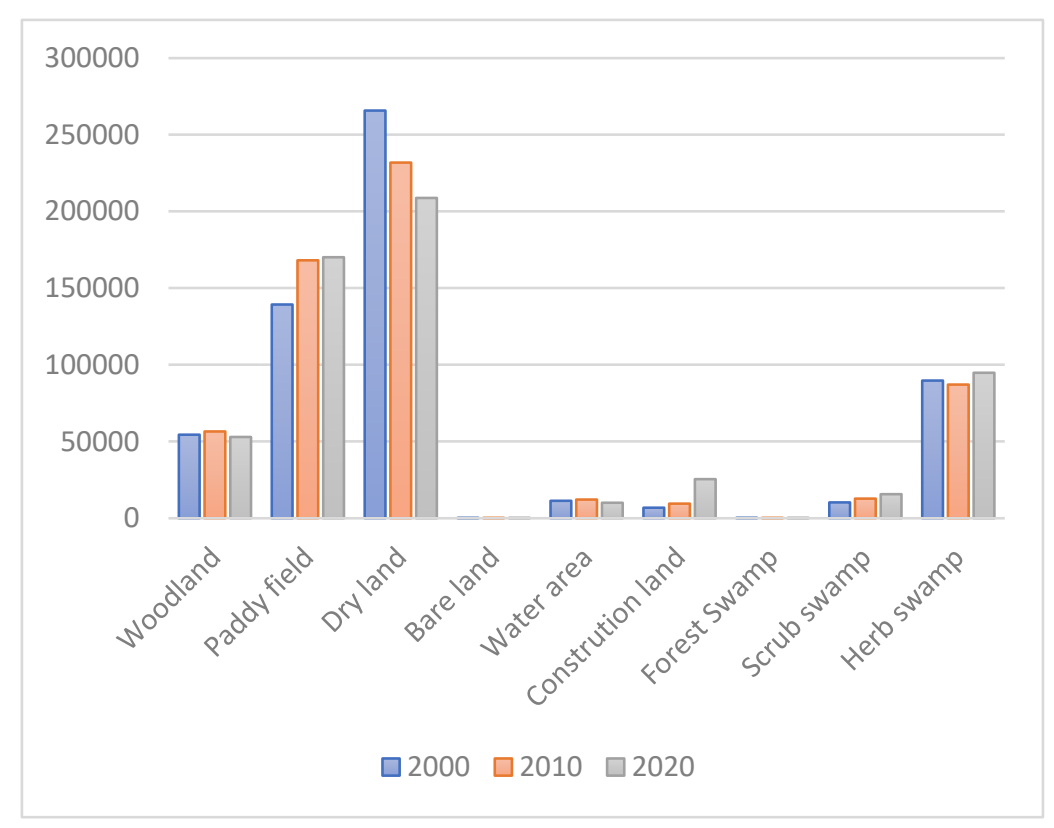

Figure 7. Protection of wetland environment scenarios land use.

\subsection{Analysis of Land Use Dynamic Degree under Three Scenarios}

Using the Markov model and introducing the transfer matrix, we predicted the land use change trend in 2020 and analyzed the dynamics of land use change in Fuyuan City from 2000 to 2020 (Table 3). 
Table 3. Land Use Dynamic Degree in Fuyuan City 2000-2020.

\begin{tabular}{|c|c|c|c|c|c|c|c|c|}
\hline & \multicolumn{2}{|c|}{$2000-2010$} & \multicolumn{2}{|c|}{ 2010-2020 Scenario 1} & \multicolumn{2}{|c|}{ 2010-2020 Scenario 2} & \multicolumn{2}{|c|}{ 2010-2020 Scenario 3} \\
\hline & $\begin{array}{c}\text { Area } \\
\text { Change }\end{array}$ & $\begin{array}{c}\text { Dynamic } \\
\text { Degree }\end{array}$ & $\begin{array}{c}\text { Area } \\
\text { Change }\end{array}$ & $\begin{array}{l}\text { Dynamic } \\
\text { Degree }\end{array}$ & $\begin{array}{c}\text { Area } \\
\text { Change }\end{array}$ & $\begin{array}{l}\text { Dynamic } \\
\text { Degree }\end{array}$ & $\begin{array}{c}\text { Area } \\
\text { Change }\end{array}$ & $\begin{array}{c}\text { Dynamic } \\
\text { Degree }\end{array}$ \\
\hline Woodland & 2100.22 & $0.35 \%$ & $-19,478.54$ & $-3.44 \%$ & $-19,496.34$ & $-3.45 \%$ & -3596.78 & $-0.64 \%$ \\
\hline Paddy field & $28,812.58$ & $1.88 \%$ & $14,886.20$ & $0.89 \%$ & $19,760.89$ & $1.18 \%$ & 2019.259 & $0.12 \%$ \\
\hline Dry land & $-33,919.47$ & $-1.16 \%$ & -857.60 & $-0.04 \%$ & $20,403.61$ & $0.88 \%$ & $-23,046.3$ & $-0.99 \%$ \\
\hline Bare land & -10.25 & $-6.34 \%$ & -0.95 & $-2.17 \%$ & -4.17 & $-9.48 \%$ & -0.95473 & $-2.17 \%$ \\
\hline Water area & 802.70 & $0.64 \%$ & 74.19 & $0.06 \%$ & -2211.44 & $-1.81 \%$ & -2080.57 & $-1.71 \%$ \\
\hline Construction land & 2648.4 & $3.49 \%$ & $15,971.17$ & $16.74 \%$ & $11,090.87$ & $11.63 \%$ & $15,968.41$ & $16.74 \%$ \\
\hline Forest swamp & -285.59 & $-8.55 \%$ & 91.70 & $50.66 \%$ & 90.71 & $50.12 \%$ & 140.1158 & $77.41 \%$ \\
\hline Scrub swamp & 2465.34 & $2.17 \%$ & 1484.25 & $1.16 \%$ & -4999.58 & $-3.90 \%$ & 2899.196 & $2.26 \%$ \\
\hline Herb swamp & -2613.84 & $-0.26 \%$ & $-12,170.16$ & $-1.40 \%$ & $-24,634.35$ & $-2.83 \%$ & 7697.815 & $0.88 \%$ \\
\hline
\end{tabular}

The results show the following:

(1) The area of construction land and forest swamps rose sharply. Between 2000 and 2010, the area of dry lands, forest swamps, and herbaceous marshes was significantly reduced; the area of forest land, paddy fields, water areas, construction land, and shrub swamps increased. In contrast, the number of forest lands decreased from 2010 to 2020, and the number of forest swamps increased. The relatively stable land types under the three scenarios are forest lands, paddy fields, dry lands, water areas, shrub swamps, and herbaceous swamps, while construction lands and forest swamps have undergone severe changes. It can be seen that the dynamic degree of construction land in the years $2000-2010$ is $3.49 \%$, while the dynamic degree in the three scenarios of 10-20 years is $16.74 \%, 11.63 \%$, and $16.74 \%$, respectively, which is nearly five times that of the $2000-2010$ period. In combination with the land use transfer matrix, the construction land for this period did not change. The forest swamp changed from a 10-year downward trend to a 20-year-long growth trend, and the dynamic degree was drastic. This shows that the urbanization process in Fuyuan City is rapid; however, it does not conflict with the level of ecological protection.

(2) In the land use planning program, the land use demand is related to the overall land use planning of Fuyuan City (2000-2020), which strictly controls the expansion of construction land and highlights the aspects of the protection of cultivated land and the ecological environment. From the comparison of the three scenarios, it can be seen that the farmland and construction land under the business-as-usual scenario increased significantly, while the wetlands decreased drastically. Scenario 2 is more protective of arable land than Scenario 1, and the areas of paddy fields and dry lands are steadily increasing compared with $\mathrm{M}$ conservation scenarios. The area of forest lands and wetlands is decreasing. Scenario 3 is more protective of wetlands than Scenario 1, in which case the conversion of paddy fields, dry land, and construction land into wetlands is the main conversion of the land use. At the same time, combining three development trends, the development trend of Scenario 3 and Scenario 1 is closer.

\subsection{Analysis of the Law of Land Use Type Transfer}

The meaning of the complete consumption coefficient is the size of the other land use area that the entire Sanjiang Plain eco-economic system will eventually consume for each additional land use area. If the complete consumption coefficient is positive, the two land use types are positively correlated, and vice versa (Table 4). 
Table 4. Land Use Complete Consumption Coefficient Matrix in Fuyuan City 2010-2020.

\begin{tabular}{cllllcc}
\hline 2010-2020 & Woodland & Farmland & Bare Land & Water Area & Construction Land & Swamp \\
\hline Woodland & 0.906462628 & -1.271873081 & -0.38985497 & -0.531454976 & -0.417626729 & -1.03020651 \\
Farmland & -1.271873081 & -3.13639098 & -0.924581601 & -1.020683182 & 0.864567169 & -2.163943398 \\
Bare Land & -0.38985497 & -0.924581601 & 1.950458268 & -0.432773249 & -0.368157356 & -0.915919922 \\
Water Area & -0.531454976 & -1.020683182 & -0.432773249 & 1.170768134 & -0.36028447 & 0.508187767 \\
Construction Land & -0.417626729 & -0.864567169 & -0.368157356 & -0.36028447 & 0.749505453 & -0.70738098 \\
Swamp & -1.03020651 & -2.163943398 & -0.915919922 & 0.508187767 & -0.70738098 & 2.19541234 \\
\hline
\end{tabular}

The results show the following:

(1) The area of returning farmland to forests remains to be solved.

According to the forecast results of 2020, for each additional unit of cultivated land area, the area of 1.271873081 units of forest land will be reduced, and the area of 2.163743398 units of wetland will be degraded. Therefore, for Fuyuan County, increasing the per unit of cultivated land will bring about more than twice the degradation of the wetland area, and the scale of the degradation of the forest land area will be greater than the increase of the cultivated land area.

(2) The regional ecological environment is relatively fragile.

At the same time, the increase in the area of unused land, mainly for sandy and bare soils, is also at the expense of other land use areas, but the total consumption factor is relatively small. As long as the reduction of 0.370266275 units of grassland will result in an increase in the bare soil area of a unit of sand, similarly, only 0.38985497 units of forest area will be reduced, and the bare soil will increase the unit area. The ecological environment of the area is relatively fragile. of. At the same time, the increase in the area of cultivated land is relatively large for the consumption and occupation of the forest land area. Multiplying the two coefficients is available. When the cultivated area is increased by one unit, it will eventually bring 3.2580 units of bare land area increase.

\section{Discussion}

\subsection{Discussion of Coordinated Development of Wetland Farmland}

(1) The internal transfer of farmland is fierce and needs to be standardized. Combining the Markov Chain model with the introduction of the transfer matrix to predict the land use pattern of 2020, it can be seen that the overall change of land use types is not obvious; however, the internal transformation between each land is intense, and the interconversion between dry land and paddy fields within the farmland is particularly obvious. The paddy field has been transferred to $41,726.4 \mathrm{hm}^{2}$ of dry land, and the dry land has been transferred to paddy fields to $68,216.3 \mathrm{hm}^{2}$. On the whole, the number of paddy fields shows an upward trend, while that of dry land shows a downward trend. Although the total amount of farmland tends to be stable and the red line of farmland changes drastically, this will cause instability in agricultural production and a low level of intensive land use. It is urgent to standardize management and rationalize the spatial layout of farmland.

(2) Wetland ecological vulnerability has increased. From 2000 to 2017, the temperature and precipitation of Fuyuan City changed significantly. The temperature gradually increased, the precipitation increased first and then decreased, and the river runoff did not change significantly. The area of the wetland decreased gradually, and the type of wetland changed drastically. According to the latest land use status classification and coding table (GB T 21010-2017), paddy fields are classified as wetlands. As a result, the problem of serious decline of the original wetland area has been alleviated, maintaining the ecological balance and sustainable development in the area. However, its ecological benefits deserve to be discussed. Combining with the transfer matrix shows that in terms of quantity, ecological protection has achieved the initial results; however, wetland ecology is fragile and sustainable development needs to be improved. 


\subsection{Discussion on the Development of Agricultural Areas}

(1) Adjustment of the policy of returning farmland to forests

The blind expansion of agricultural land will inevitably lead to more significant degradation of forest land and wetlands, and blind development in the region will bring about tremendous damage to the natural environment. Similarly, in order to increase the area of a forest or the area of a wetland, it is necessary to use a large amount of land for returning farmland to forests. Therefore, the pressure on returning farmland to forests in this area is relatively high. At present, the new land use planning of Heilongjiang Province will result in the consumption of forest land, wetland, and grassland, which will be $6.8102 \mathrm{hm}^{2}, 674.214 \mathrm{hm}^{2}$, and $6,157,762 \mathrm{hm}^{2}$, respectively. A large amount of ecological resources will be consumed. The ecological environment will have more serious destructive effects on the basis of the present. The original land use plan should be revised. In order to achieve the goal of mutual coordination between agricultural development and ecological environmental protection, the cultivation of ecological forests should be increased to curb the trend of reduction of wetland area and functional degradation. Under this premise, other agricultural land should be arranged.

(2) Economic development in agricultural areas

Land use planning is a public affair which aims to coordinate land use and resolve conflicts of interest of different stakeholders and groups [26]. Most of the world's agricultural regions such as Fuyuan are facing unprecedented questions regarding urban expansion. The three forecast scenarios show that the city's scale is expanding, although there is no environmental damage. It has not stimulated economic development. The slowing effect of urban concentration felt by the economic recession has been a key issue on the regional agenda. One of the top regional priorities lies in diversifying the land use of Fuyuan, in an attempt to create a diversified offer, attracting young workforce opportunities, or integrating stakeholder choices and multicriteria analysis to support land use planning.

\section{Conclusions}

This paper uses the Markov Chain model and introduces the transfer matrix to predict the trend of land use pattern change in 2020. The proportion of cultivated land in the area exceeds $70 \%$, which occupies an advantageous position. The land use structure is dominated by farmland, which is in line with the regional economic and social development characteristics of the Fuyuan Municipal Government in its efforts to build "one land and three districts" and develop "five major industries".

To further implement ecological protection policies and balance the harmonious development of farmland and wetlands, the Fuyuan City Land Use Ecological Protection Plan can be divided into three steps:

(1) Intensive development and utilization of cultivated land, rationalization of space layout for land use, and determination of the farmland protection red line.

(2) Herb swamps are the most easily converted land types, and restoration of wetlands can begin with herbaceous swamps.

(3) Increase and accelerate the area of forest swamps to protect biodiversity.

Land use/land cover changes are caused by natural factors and human activities. How to coordinate the relationship between land use and ecological construction is an issue that we urgently need to solve. This paper proposes a method of combining a multiple scenarios prediction with the general land use planning in Fuyuan City, which will be used for the quantitative analysis of urban land use scenarios in the future. The modeling based on different scenarios will produce new results. Through the comparative analysis of the overall land planning and prediction results of Fuyuan City, it can be found that the current land use planning of Heilongjiang province will cause a large number of ecological resources to be consumed due to the new planning of agricultural land, and the original 
land use planning should be modified to some extent. This method of scenario simulation can be used in a wider range of land use analysis and is recommended for continued use in future research areas. However, the research method used in this paper is only for the land management department to verify whether the formulation of the land policy is reasonable, and the spatial planning and layout of land use in Fuyuan City will be further developed in the next study.

Author Contributions: Conceptualization, X.Z. (Xun Zhu) and B.Z.; Methodology, X.Z. (Xun Zhu) and X.Z (Xiaolong Zhao); Software, R.Z.; Validation, B.Z., X.Z. (Xun Zhu) and R.Z.; Formal Analysis, B.Z.; Investigation, X.Z.; Resources, X.Z. (Xun Zhu); Data Curation, B.Z. and R.Z.; Writing-Original Draft Preparation, B.Z.; Writing-Review \& Editing, B.Z.; Visualization, Xiaolong.Z; Supervision, X.Z. (Xun Zhu); Project Administration, X.Z. (Xun Zhu); Funding Acquisition, X.Z (Xun Zhu).

Funding: This research was funded by Harbin Science and Technology Innovation Talent Project. Grant number 2016RAQXJ078.

Conflicts of Interest: The authors declare no conflicts of interest.

\section{References}

1. Peña, L.; Onaindia, M.; Fernández de Manuel, B.; Ametzaga-Arregi, I.; Casado-Arzuaga, I. Analysing the Synergies and Trade-Offs between Ecosystem Services to Reorient Land Use Planning in Metropolitan Bilbao (Northern Spain). Sustainability 2018, 10, 4376. [CrossRef]

2. Williams, M. Wetlands: A Threatened Landscape; Blackwell: Oxford, UK, 1990.

3. Liu, X.T. Water Storage and Flood Control Function in Sanjiang Plain Marsh Wetland. Wetl. Sci. 2007, 1, 64-68.

4. An, N.; Gao, N.Y.; Liu, C.E. Wetland degradation in China: Causes, evaluation, and protection measures. Chin. J. Ecol. 2008, 5, 821-828.

5. Zhao, S.Q.; Peng, C.H.; Jiang, H.; Tian, D.L.; Lei, X.D.; Zhou, X.L. Land use change in Asia and the ecological consequences. Ecol. Res. 2006, 21, 890-896. [CrossRef]

6. An, S.Q.; Li, H.B.; Guan, B.H.; Zhou, C.F.; Wang, Z.S.; Deng, Z.F.; Zhi, Y.B.; Liu, Y.H.; Xu, C.; Fang, S.B.; et al. China's natural wetlands: Past problems, current status, and future challenges. Ambio 2007, 36, 335-342. [CrossRef]

7. Fang, J.Y.; Rao, S.; Zhao, S.Q. Human-induced long-term changes in the lakes of the Jianghan Plain, central Yangtze. Front. Ecol. Environ. 2005, 3, 186-192. [CrossRef]

8. Scanlon, B.R.; Jolly, L.; Sophocleous, M.; Zhang, L. Global impacts of conversions from natural to agricultural ecosystems on water resources: Quantity versus quality. Water Resour. Res. 2007, 43, W03437. [CrossRef]

9. Saunders, M.J.; Kansiime, F.; Jones, M.B. Agricultural encroachment: Implications for carbon sequestration in tropical African wetlands. Glob. Chang. Biol. 2012, 18, 1312-1321. [CrossRef]

10. Cao, K.; Huang, B.; Wang, S.W.; Lin, H. Sustainable land use optimization using Boundary-based Fast Genetic Algorithm. Comput. Environ. Urban Syst. 2012, 36, 257-269. [CrossRef]

11. Liu, Y.L.; Liu, D.F.; Liu, Y.F.; He, J.H.; Jiao, L.M.; Chen, Y.Y.; Hong, X.F. Rural land use spatial allocation in the semiarid loess hilly area in China: Using a Particle Swarm Optimization model equipped with multi-objective optimization techniques. Sci. China Earth Sci. 2012, 55, 1166-1177. [CrossRef]

12. Hu, M.G.; Fu, X.Y.; Zhang, S.Q. Simulation of Land Cover Change in Momoge Wetland Based on Cellular Automata. Resour. Sci. 2007, 29, 142-148.

13. Liu, X.P.; Li, X.; Peng, X.J. Application of "Niche" Cellular Automata in Land Sustainable Planning Model. Acta Ecol. Sin. 2007, 6, 2391-2402.

14. Tong, C.; Hao, D.Y.; Gao, X.; Jiang, Q.H.; Yong, S.P. Prediction of Grassland Degradation Pattern in Xilin River Basin Based on Markov Model. J. Nat. Resour. 2002, 4, 488-493.

15. Zhao, J.J.; Zhang, H.Y.; Qiao, Z.H.; Zhang, Z.X.; Hou, G.L. Dynamic Simulation of Land Cover Change in Xianghai Wetland Based on CA-Markov Model. J. Nat. Resour. 2009, 24, 2178-2186.

16. Xu, Y.Q.; Luo, D.; Guo, H.F.; Zhou, D. Multi-situational Simulation of Land Use Spatial Layout Based on CLUE-S Model: A Case Study of Yuzhong County, Gansu Province. Acta Sci. Nat. Univ. Pekin. 2013, 49, 523-529.

17. Xu, X.J.; Liu, H.Y.; Lin, Z.S.; Liu, J.X.; Li, L.H. Scenario Analysis of Land Use Change Based on CA-MARKOV Model in The Coastal Area of Jiangsu. Res. Soil Water Conserv. 2017, 24, 213-218, 225. 
18. de Noronha Vaz, E.; Nijkamp, P.; Painho, M.; Caetano, M. A multi-scenario forecast of urban change: A study on urban growth in the Algarve. Landsc. Urban Plan. 2012, 104, 201-211. [CrossRef]

19. Song, K.; Liu, D.; Wang, Z.; Zhang, B.; Jin, C.; Li, F.; Liu, H. Land use change and driving force in Sanjiang Plain since 1954. Acta Geogr. Sin. 2008, 1, 93-104.

20. Na, S.; Zhang, J.; Yan, H. Discussion on the Construction of Wetland Ecological Environment in Sanjiang Plain. J. Northeast For. Univ. 2004, 2, 78-80.

21. Wang, A.; Zhang, S.; Zhang, B. Spatial pattern change of marsh wetland landscape in Sanjiang Plain. Acta Ecol. Sin. 2003, 2, 237-243.

22. Liu, H.; Zhang, S.; Lv, X. Study on the Change Process of Wetland Landscape in Naoli River Basin since the 1980s. J. Nat. Resour. 2002, 6, 698-705.

23. Deng, W.; Luo, X.; He, Y.; Luan, Z. Driving Force Analysis of Runoff Evolution of Marsh Rivers in Sanjiang Plain. Acta Geogr. Sin. 2002, 5, 603-610.

24. Wei, Q.; Yang, L.; Liu, Y.; Qi, L.; Lu, X. Analysis of Driving Factors of Wetland Area Reduction in Sanjiang Plain. J. Wetl. Sci. 2014, 12, 766-771.

25. Koneff, M.D.; Royle, J.A. Modeling wetland change along the United States Atlantic Coast. Ecol. Model. 2004, 177, 41-59. [CrossRef]

26. Qu, Z.; Lu, Y.; Jiang, Z.; Bassett, E.; Tan, T. A Psychological Approach to 'Public Perception' of Land-Use Planning: A Case Study of Jiangsu Province, China. Sustainability 2018, 10, 3056. [CrossRef]

(C) 2019 by the authors. Licensee MDPI, Basel, Switzerland. This article is an open access article distributed under the terms and conditions of the Creative Commons Attribution (CC BY) license (http://creativecommons.org/licenses/by/4.0/). 